\title{
Clinical Study \\ The Cost Implications of Replacing Soda Lime with Amsorb Plus in Clinical Practice
}

\author{
Osman Ahmed and Stephen Mannion \\ Department of Anesthesiology, South Infirmary-Victoria University Hospital, Cork, Ireland \\ Correspondence should be addressed to Stephen Mannion, mannionstephen@gmail.com
}

Received 31 August 2011; Accepted 27 September 2011

Academic Editor: K. Higa

Copyright ( $) 2011$ O. Ahmed and S. Mannion. This is an open access article distributed under the Creative Commons Attribution License, which permits unrestricted use, distribution, and reproduction in any medium, provided the original work is properly cited.

\begin{abstract}
Background and Goal of the Study. Desiccated soda lime is known to produce toxic compounds when interacting with volatile anesthetic agents. Amsorb Plus does not produce these but is more expensive per unit weight. Materials and Methods. In a prospective cross-over study, we evaluated the cost of using soda lime (Spherasorb, Intersurgical, UK) and Amsorb Plus. In four operating theatres over two 4-week periods, one for each product, we measured sevoflurane consumption, amount of absorbent used $(\mathrm{kg})$, and amount of waste disposal $(\mathrm{kg})$. Soda lime was changed weekly, and Amsorb Plus once colour change happened. Both were changed if inspired $\mathrm{CO}_{2}$ occurred. Low fresh gas flows were encouraged with Amsorb Plus. Results and Discussion. The total costs over each four-week period were $€ 4375.69$ and $€ 3150.94$ for soda lime and Amsorb Plus respectively. Reduced cost during Amsorb Plus period (28\%) was due to (1) less sevoflurane consumption, (2) fewer Amsorb Plus changes because of reliable colour change, and (3) cheaper domestic waste disposal of Amsorb Plus as it is inert. Conclusion. We demonstrated Amsorb Plus to be a cost-efficient alternative to soda lime in everyday clinical practice.
\end{abstract}

\section{Introduction}

Desiccated soda lime is known to produce toxic compounds when interacting with volatile anesthetic agents $[1,2]$. Sevoflurane degradation results in the formation of compound $\mathrm{A}$ which is reported to be nephrotoxic in rats [3]. Formaldehyde is also produced from sevoflurane degradation [4]. On the other hand, desflurane, enflurane, and isoflurane produce carbon monoxide when degraded by desiccated or partially desiccated soda lime, and serious carbon monoxide poisoning with neurologic injury has been reported with desflurane anesthesia [5]. Destruction of volatile anesthetics could lead to diminished inspiratory concentration with resultant delay in induction of anesthesia and increased anesthetic costs [6].

Carbon monoxide poisoning is more frequent on Mondays, when the anesthetic machine may not be used over a weekend and during the first case in an operating list because of the possibility that the fresh gas flow might have been left open overnight which results in absorbent desiccation [7].

Strong alkalis namely sodium and potassium hydroxide are components of soda lime, and they act to abstract a labile proton from the anesthetic molecule rendering them susceptible to degradation. Proton abstraction and hence degradation occurs more with potassium than sodium hydroxide [8].

Elimination of strong alkalis from desiccated soda lime diminishes the productions of adverse by-products but at the same time does not compromise the efficiency of carbon dioxide absorption $[8,9]$.

Amsorb Plus (Armstrong Medical Ltd., Coleraine, Northern Ireland) is a novel $\mathrm{CO}_{2}$ absorber introduced by Murray et al. in 1999, that does not contain strong alkalis and so does not have these drawbacks $[1,10]$. However, it is more expensive per unit weight than soda lime. This cost might be offset by lower sevoflurane use as there is no risk of compound A formation at lower flows permitting fresh gas flows of $2 \mathrm{~L} / \mathrm{min}$ or less-fewer product changes are required as the colour change is uniform and stable, and there is cheaper waste disposal as Amsorb Plus is inert and can be disposed off in domestic waste rather than soda lime which is disposed of in health care waste. There are also no concerns with its handling, unlike for soda lime which is caustic. 
Many studies have compared Amsorb Plus to conventional soda lime in terms of efficiency and safety regarding the production of compound A and carbon monoxide [1, $9,10]$. However, none has investigated the cost implications of replacing soda lime with Amsorb Plus in daily clinical practice.

In a prospective cross-over study, we investigated the cost of replacing soda lime with Amsorb Plus in our institution, with regard to the cost of the (1) $\mathrm{CO}_{2}$ absorbent, (2) sevoflurane, and (3) waste disposal.

\section{Materials and Methods}

We conducted a prospective cross-over study in our institution in the main theatre complex of South Infirmary-Victoria University Hospital, Cork, Ireland. The study was approved by the hospital's Drugs \& Therapeutic Review Board. The study was conducted in four operating theatres over two 4week periods, one for each product. Sevoflurane (Sevorane, Abbott Laboratories Ltd., Dublin, Ireland, $250 \mathrm{~mL}$ bottles) consumption, amount of absorbent used (kg), and amount of waste disposal (kg) were measured as the primary outcomes.

The four operating theatres serve three different specialities: ENT surgery, general surgery, and plastic surgery.

Three of the operating theatres have Datex Ohmeda Aestiva (Datex-Ohmeda Aestiva/5, GE Healthcare, USA) anesthetic machines, each with a double jerrican (1 kilograms capacity each). The anesthetic machine in the other theatre is a Datex Ohmeda Aespire (Aespire 7100, GE Healthcare, USA) with a single jerrican (1 kilogram capacity). Prefilled canisters and not loose product were used for both products throughout the study periods.

A departmental guideline and education sessions were given to all anesthesiologists in the department prior to the first study period and again at the start of the second period, advising on fresh gas flows and product changes for each absorbent. According to the guideline, soda lime (Spherasorb, Intersurgical, United Kingdom) was changed weekly on Mondays [11]. Amsorb Plus was changed once uniform colour change happened. Both were changed if inspired $\mathrm{CO}_{2}$ occurred with total fresh gas flow of $4 \mathrm{~L} / \mathrm{min}$ or more. Low flows $(<2 \mathrm{~L} / \mathrm{min})$ were encouraged with Amsorb Plus, while flows of between 2 and $4 \mathrm{~L} / \mathrm{min}$ were advised with soda lime. End tidal agent monitoring was performed in all patients.

The amount of product used in each period, sevoflurane consumption, and the amount of waste disposal were measured, and the costs of each of these endpoints and added to determine the total cost.

The number of patients having general anesthesia (GA) was noted. As toxic by-products have been linked to side effects, the incidence of postoperative nausea and vomiting (PONV) and headache in the PACU was recorded.

A survey of all anesthesiologists involved was conducted at the end of the study period. All anaesthesiologists involved over both periods were requested to fill in a questionnaire which comprised of three questions with three optional answers-yes, no, do not know. Question 1: Did you notice any difference between using soda lime and Amsorb Plus? and Question 2: do you think Amsorb Plus is easy to use and dispose of? Question 3: will you use Amsorb Plus in the future?

Statistical analysis using a two-tailed Fisher's exact test for smaller sample sizes was used (Graphpad InStat, Graphpad Software, Calif, United States of America). $P$ value $<0.05$ was considered significant.

\section{Results}

Table 1 shows the the costs incurred for each endpoint as well as the number of patients receiving GA during each trial period. Overall, the total costs over each four-week period were $€ 4375.69$ and $€ 3150.94$ for soda lime and Amsorb Plus, respectively. There were reduced costs for all endpoints measured; the greatest savings were in sevoflurane consumption, $€ 3839.85$ and $€ 2852.46$ for soda lime and Amsorb Plus, respectively although the number of $250 \mathrm{~mL}$ bottles used in each group was not significant. Amsorb Plus product cost was also less than soda lime ( $€ 505.24$ compared to $€ 296.38)$, as a result of significantly fewer canister changes $(P<0.006)$.

We found no differences in clinical side effects as shown in Table 2.

Of the 11 anesthesiologists involved in the 8-week timeframe and who all received survey questionnaires, 10 responses were returned ( $91 \%$ response rate).

7 anesthesiologists reported that they found a difference using Amsorb Plus compared with soda, while 3 found no difference. All reported that Amsorb Plus was easy to use and dispose of. 8 will use Amsorb Plus in the future with 2 not knowing at that time.

\section{Discussion}

Although Amsorb Plus was more expensive per unit product than soda lime, the overall cost of using Amsorb Plus was less. There were a number of reasons for this.

As the colour change of desiccated Amsorb Plus is more reliable than soda lime $[12,13]$, canister changes were limited to actual changes as compared with international recommendations of changing soda lime on fixed days, usually Mondays [11] so as to remove the risk of desiccation over the weekend. This has been demonstrated by our findings showing the large amount of soda lime used compared to Amsorb Plus. Reliable colour indication of absorbent exhaustion for Amsorb Plus may have contributed to less product changes. Another factor could be the difference in particle size and efficiency of the product though these were not investigated in our study.

The total number of patients undergone GA during soda lime and Amsorb Plus were 231 and 236, respectively, but sevoflurane cost was less with Amsorb Plus compared to soda lime. The savings from lower sevoflurane usage may have been as a result of lower fresh gas flows used during Amsorb Plus trial, but the exact flows were not measured so as to 
Table 1: Cost comparison between soda lime and Amsorb Plus.

\begin{tabular}{|c|c|c|c|}
\hline & Soda lime & Amsorb Plus & $P$ value \\
\hline Number of GAs & 231 patients & 236 patients & \\
\hline \multirow[t]{2}{*}{ Product used and cost } & 34 canisters & 14 canisters & 0.006 \\
\hline & $\begin{array}{l}€ 505.24 \\
(€ 14.86 / \text { canister })\end{array}$ & $\begin{array}{l}€ 296.38 \\
(€ 21.17 / \text { canister })\end{array}$ & (number of canisters) \\
\hline Sevoflurane bottles & 35 bottles & 26 bottles & 0.22 \\
\hline (250 mls) and cost & $\begin{array}{l}€ 3839.85 \\
(€ 109.71 / \text { bottle })\end{array}$ & $\begin{array}{l}€ 2852.46 \\
(€ 109.71 / \text { bottle })\end{array}$ & (number of bottles) \\
\hline \multirow[t]{2}{*}{ Waste and cost } & 34 kilograms & 14 kilograms & $0.006(\mathrm{kgs})$ \\
\hline & $€ 30.6\left(€ 0.9 / \mathrm{kg}^{*}\right)$ & $€ 2.1\left(€ 0.15 / \mathrm{kg}^{\wedge}\right)$ & \\
\hline Total cost (4 weeks) & $€ 4375.69$ & $€ 3150.94$ & \\
\hline
\end{tabular}

TABLE 2: It shows the number of patients complaining of headache or PONV during each period.

\begin{tabular}{lccc}
\hline & Soda lime period & $\begin{array}{c}\text { Amsorb Plus } \\
\text { period }\end{array}$ & $P$ value \\
\hline Headache & 7 & 4 & 0.22 \\
PONV & 14 & 13 & 0.85 \\
\hline
\end{tabular}

replicate everyday clinical practice as realistic as possible. Using low flows (less than $2 \mathrm{~L} / \mathrm{min}$ ) with sevoflurane when using soda lime as carbon dioxide absorbent carries the risk of compound A production; although low flows might be used in other institutions the trend in our institution is that the risk of compound A production cannot be ignored with low flows and that debatable clinical effects represent a potential risk. Although low flows with Amsorb Plus were encouraged as part of the departmental guideline and educational sessions were given on the benefits of lower flows, the we did not assess individual anesthesiologist's adherence to same. Of note, $70 \%$ of anesthesiologists surveyed noticed a difference in their practice, so lower flows may have been used with Amsorb Plus. Ensuring that all anesthesiologists adhered to the guideline of flow rates less than $2 \mathrm{~L} / \mathrm{min}$ would have been impractical and not feasible in normal clinical practice, which was the environment we wanted to assess the costs of use of either product. Sevoflurane degradation by soda lime and not Amsorb Plus may also have contributed to the lower sevoflurane costs during Amsorb Plus period although the fraction degraded was not measured.

As Amsorb Plus is inert, it is disposed of in domestic waste and does not cause skin or mucous membrane irritation mainly because of the absence of a strong alkali $[1,10]$. Although the amounts of product for waste disposal are relatively small, there are still savings for Amsorb Plus on the the cost of soda lime disposal because soda lime is disposed of as healthcare waste which is more expensive per unit weight.

Although Amsorb Plus does not produce toxic byproducts such as formaldehyde [4] or carbon monoxide $[1,2,4,7-9]$, we found no difference in the incidence of possible side effects of these (headache and PONV) as shown in Table 2. However, these endpoints were not the primary outcome of this study, nor was the study powered to examine these effects. Our incidence of PONV was less than $10 \%$ for both groups. This low value can be explained by our institutional policy of using a simplified risk scoring policy for PONV prevention as well as the fact that only PONV occurring in the PACU was recorded and patients were not followed up after that. Further work is needed to evaluate these endpoints.

All anesthesiologists surveyed reported that Amsorb Plus was easy to use, easy to dispose, of and requiring less canister changes, with $80 \%$ reporting that they would use in the future. As a result of our findings, our institution has replaced soda lime with Amsorb Plus in all our theatres.

\section{Conclusion}

The safety benefits of replacing soda lime with Amsorb Plus are already well documented in literature $[1-3,5,6,9,10]$; however, the cost implications of such replacement have been of concern for many institutions and may be a reason for delaying its widespread use in clinical practice.

In a prospective cross-over study, we demonstrated that Amsorb Plus is a suitable, cost-efficient alternative to soda lime in everyday clinical practice.

\section{Disclosure}

The authors have no financial or other conflicts, and Amsorb Plus was bought through normal procurement procedures for the hospital.

\section{References}

[1] E. D. Kharasch, K. M. Powers, and A. A. Artru, "Comparison of amsorb $\AA$, sodalime, and baralyme $\AA$ degradation of volatile anesthetics and formation of carbon monoxide and compound A in swine in vivo," Anesthesiology, vol. 96, no. 1, pp. 173-182, 2002.

[2] R. I. Mazze and R. L. Jamison, "Low-flow (1 1/min) sevoflurane: is it safe?" Anesthesiology, vol. 86, no. 6, pp. 1225-1227, 1997. 
[3] M. Morio, K. Fujii, N. Satoh et al., "Reaction of sevoflurane and its degradation products with soda lime: toxicity of the byproducts," Anesthesiology, vol. 77, no. 6, pp. 1155-1164, 1992.

[4] F. Marini, I. Bellugi, D. Gambi et al., "Compound A, formaldehyde and methanol concentrations during low-flow sevoflurane anaesthesia: comparison of three carbon dioxide absorbers," Acta Anaesthesiologica Scandinavica, vol. 51, no. 5, pp. 625-632, 2007.

[5] "Carbon monoxide expostures during inhalation anaesthesia: the interaction between halogenated anaesthetic agents and carbon dioxide absorbents," Health Devices, vol. 27, pp. 402404, 1998.

[6] W. Funk, M. Gruber, K. Wild, and J. Hobbhahn, "Dry soda lime markedly degrades sevoflurane during simulated inhalation induction," British Journal of Anaesthesia, vol. 82, no. 2, pp. 193-198, 1999.

[7] H. J. Woehlck, M. Dunning III, and L. A. Connolly, "Reduction in the incidence of carbon monoxide exposures in humans undergoing general anesthesia," Anesthesiology, vol. 87, no. 2, pp. 228-234, 1997.

[8] P. J. Baxter, K. Garton, and E. D. Kharasch, "Mechanistic aspects of carbon monoxide formation from volatile anesthetics," Anesthesiology, vol. 89, no. 4, pp. 929-941, 1998.

[9] M. A. Neumann, M. J. Laster, R. B. Weiskopf et al., "The elimination of sodium and potassium hydroxides from desiccated soda lime diminishes degradation of desflurane to carbon monoxide and sevoflurane to compound A but does not compromise carbon dioxide absorption," Anesthesia \& Analgesia, vol. 89, no. 3, pp. 768-773, 1999.

[10] J. M. Murray, C. W. Renfrew, A. Bedi, C. B. McCrystal, D. S. Jones, and J. P. H. Fee, "Amsorb: a new carbon dioxide absorbent for use in anesthetic breathing systems," Anesthesiology, vol. 91, no. 5, pp. 1342-1348, 1999.

[11] http://www.apsf.org/newsletters/pdf/summer2005.pdf.

[12] E. Knolle, W. Linert, and H. Gilly, "The color change in $\mathrm{CO}_{2}$ absorbents on drying: an invitro study using moisture analysis," Anesthesia \& Analgesia, vol. 97, no. 1, pp. 151-155, 2003.

[13] E. Knolle, W. Linert, and H. Gilly, "Using Amsorb to detect dehydration of $\mathrm{CO}_{2}$ absorbents containing strong base," Anesthesiology, vol. 97, no. 2, pp. 454-459, 2002. 


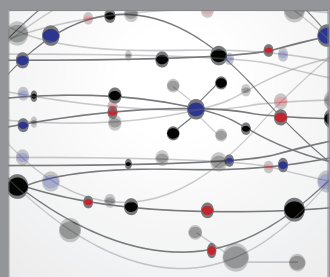

The Scientific World Journal
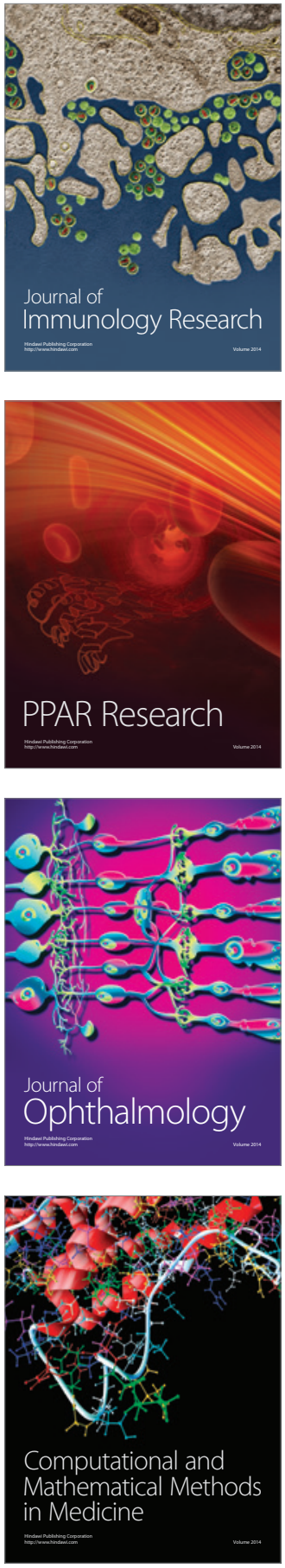

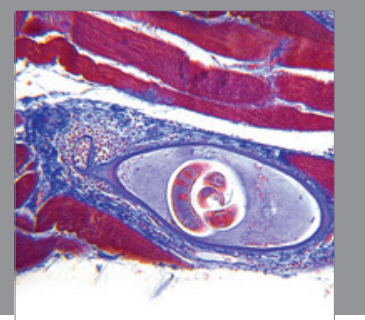

Gastroenterology

Research and Practice
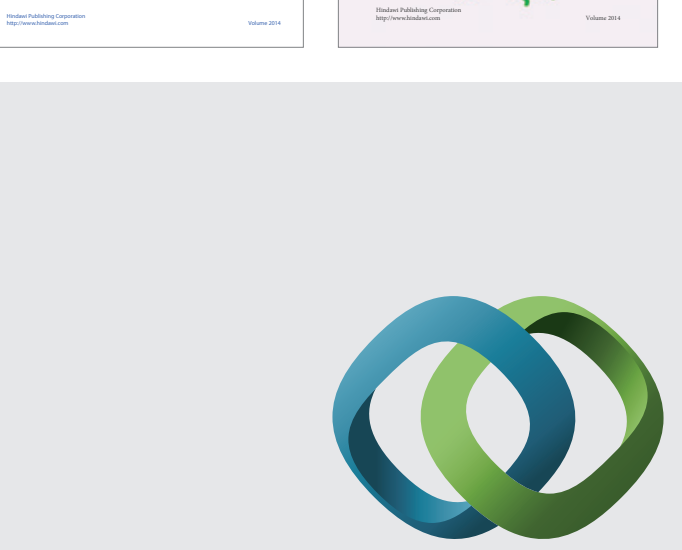

\section{Hindawi}

Submit your manuscripts at

http://www.hindawi.com
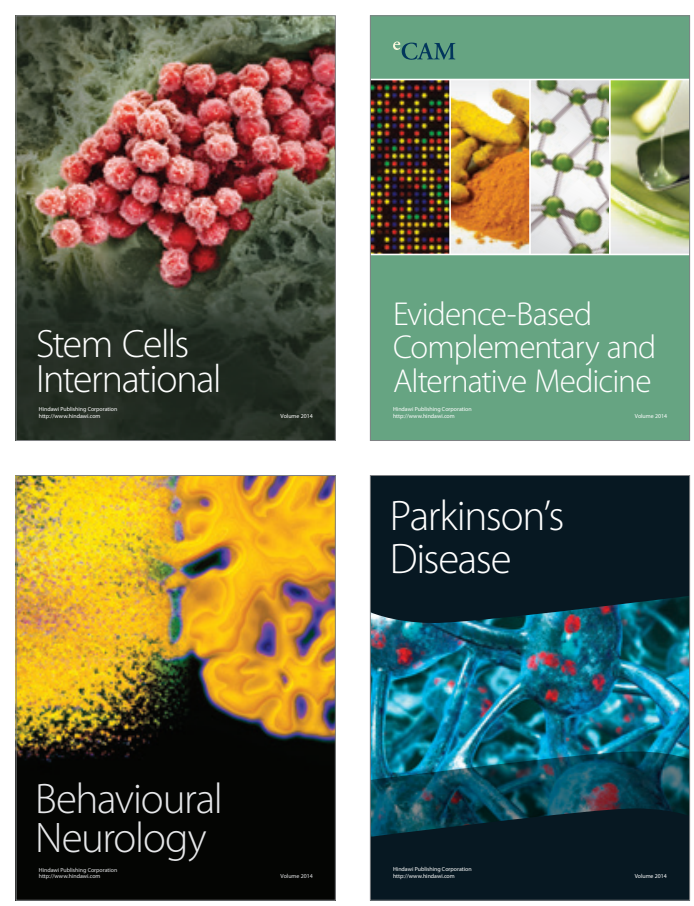

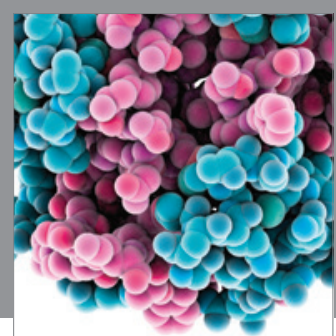

Journal of
Diabetes Research

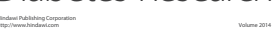

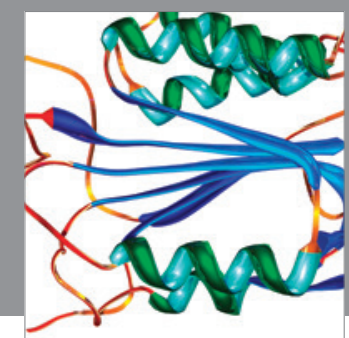

Disease Markers
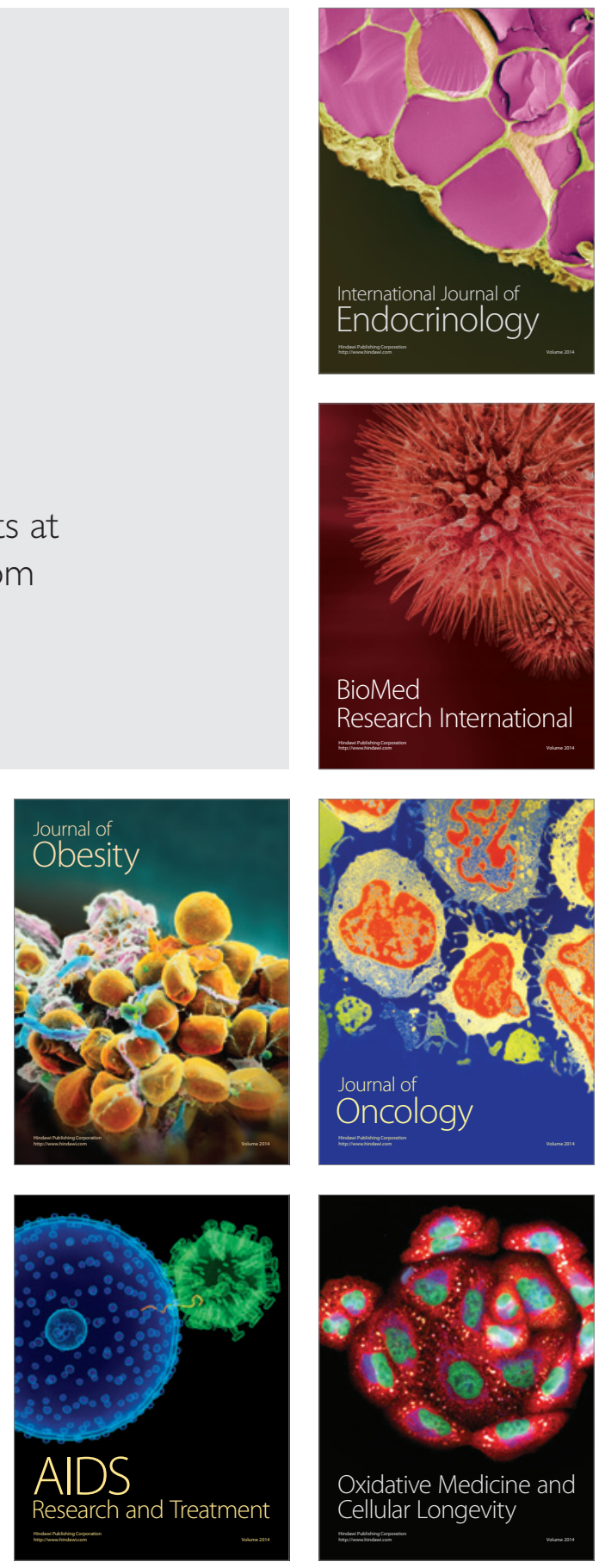